\title{
Proteomic analysis of plasma after branched chain enriched mixture supplementation in mice
}

\author{
Lorenza Brocca', Anna Mascaro ${ }^{1}$ and Giuseppe D'Antona ${ }^{1,2^{*}}$
}

\begin{abstract}
Background: Branched chain amino acid (BCAA) supplementation is a recently identified strategy to promote longevity in mice. A proteomic approach was used to identify proteins which are differentially expressed in the sera of mice following supplementation with selected branched chain amino acid enriched mixture (BCAAem).

Findings: 12 male mice (C57Bl6, 9 months-old) were randomly assigned to unsupplemented (Control, $\mathrm{n}=6$ ) and supplemented (BCAA, $n=6,0.1 \mathrm{mg} / \mathrm{gr} /$ day in drink water for 4 weeks). At the end of treatment total plasma samples from Control and BCAAem mice were separated by two-dimensional gel electrophoresis (2-DE). After staining, the gels were imaged and differential protein expression patterns were interrogated using image analysis software. Spots showing a different expression level were identified through a comparison with 2D maps found in databases officially recognized (ExPASy).

Master gels of Control and BCAA mice exhibited slightly different 2-DE patterns as only 10 spots out of 500 appeared differentially expressed: 8 were upregulated (corresponding to Apolipoprotein A-I (APOA1), Complement factor B, Complement C3, Immunoglobulin light chain) and 2 appeared downregulated (Alpha-1-antitrypsin and unknown).
\end{abstract}

Conclusions: Supplementation with BCAAem in mice results in a slight perturbation of the host serum proteome. Of particular interest is the increased Apolipoprotein A-I (APOAI) following treatment.

Keywords: Amino acids, Proteome, Dietary supplements

\section{Background}

In ageing common metabolic, inflammatory, cardiovascular and neurodegenerative diseases, ultimately reduce healthspan and lifespan.

Regardless of the mechanism, a common feature of aging-related diseases is the involvement of metabolic systems in general, and the mitochondria in particular [1].

We have recently demonstrated that supplementation of aged mice with a branched-chain amino acid-enriched mixture (BCAAem) promotes mitochondrial biogenesis and function, with a reduced radical oxygen species (ROS) production and extension of mean survival [2]. All the BCAAem-mediated effects appeared to be considerably enhanced by combined resistance exercise training and strongly attenuated in endothelial nitric oxide synthase null-mutant mice $\left(\mathrm{eNOS}^{-/-}\right)$or after rapamycin, an

\footnotetext{
* Correspondence: gdantona@unipv.it

${ }^{1}$ Department of Molecular Medicine, University of Pavia, Pavia, Italy

${ }^{2}$ LUSAMMR, Laboratory for Motor Activities in Rare Diseases, Sport Medicine Centre Voghera, Voghera, Italy
}

inhibitor of mammalian target of rapamycin (mTOR) pathway. Although a direct metabolic effect of BCAAem on skeletal muscles contributes to the overall change in mitochondrial biogenesis and function and antioxidant activity [2], an indirect tissue effect mediated or sustained by circulating factors may contribute to the observed effects on survival or, simply, may represent footprint biomarkers of the nutritional strategy. This concern might also be considered in order to clarify the mechanisms underlying the known beneficial effect of BCAA supplementation before and after exercise mainly consisting in decreased exercise-induced muscle damage and promoted muscle protein synthesis [3]. Indeed initial reports highlight the effects of BCAA enriched mixtures supplementation on the pattern of circulating factors such as cytokines [4] and hormones (i.e. GH) following exercise in humans [5].

Here we used plasma proteomics to investigate whether dietary supplementation with BCAAem would impact on the plasma protein profile thus defining a 
plasma biomarker fingerprint of supplementation in adult sedentary mice.

\section{Methods}

12 male mice (F2 Hybrid B6.129S2 obtained from crossing C57BL/6 J and 129S1/SvImJ mice, 9 month at the beginning of treatment) (The Jackson Laboratory), housed one per cage and maintained at $20^{\circ} \mathrm{C}, 12 \mathrm{~h} /$ $12 \mathrm{~h}$ day/night cycles, were treated according to the EU guidelines and with the approval of the Institutional Ethical Committee. Animals were given unrestricted access to a standard diet (4.3 $\mathrm{kcal} \%$ fat, $18.8 \mathrm{kcal} \%$ protein, 76.9 kcal\% carbohydrate, Laboratorio Dottori Piccioni) and were randomly assigned to two groups: unsupplemented $(\mathrm{Ct}, \mathrm{n}=6)$ and supplemented (BCAA, $0.1 \mathrm{gr} / \mathrm{kg} /$ day in drinking water, $n=6$ ). Consumption of food and water was monitored along the treatment and appeared not statistical different between groups. (Ct, $3.1 \pm 0.01 \mathrm{~g} /$ day and $6.5 \pm 1.0 \mathrm{ml} /$ day, $\mathrm{n}=6$; BCAA, $3.3 \pm 0.03 \mathrm{~g} /$ day and $6.0 \pm 1.2 \mathrm{ml} /$ day, $\mathrm{n}=6$ respectively $\mathrm{p}>0.05)$. The amino acid supplement BCAAem (composition: $31.25 \%$ leucine, $16.25 \%$ lysine, $15.52 \%$ valine, $15.52 \%$ isoleucine, $8.75 \%$ threonine, $3.75 \%$ cysteine, $3.75 \%$ histidine, $2.6 \%$ phenylalanine, $1.25 \%$ methionine, $0.75 \%$ tyrosine, $0.5 \%$ tryptophan) was administered with a daily dose of 0.1 $\mathrm{gr} / \mathrm{kg}$ body weight dissolved in tap water on basis of the previously monitored daily drinking (average drinking $6.65 \pm 1.5 \mathrm{ml} /$ day, $\mathrm{n}=12$ ).

At the end of treatment in the late morning and after at least $4 \mathrm{~h}$ fasting, mice were weighted $(\mathrm{Ct}, 30 \pm 1 \mathrm{~g}$ $\mathrm{n}=6$; BCAA $29 \pm 1.2 \mathrm{~g} \mathrm{n}=6, \mathrm{p}>0.05)$ and a blood sample (around $400 \mu \mathrm{L}$ ) was withdrawn from the retro orbital sinus of each mouse under slight ether anesthesia.

The samples were centrifuged at $8000 \mathrm{~g}$ for $15 \mathrm{~min}$ in order to separate the serum fractions which were frozen in liquid nitrogen and maintained at $-80^{\circ} \mathrm{C}$ for subsequent analysis.

\section{Two-dimensional electrophoresis analysis}

Protein concentration of each sample were determine using the $D C$ Protein Assay (by Bio-Rad), a colorimetric assay based on the method of Lowry [6].

$100 \mu \mathrm{g}$ of protein for each sample ( $\mathrm{Ct}$ and BCAA) were precipitated in 8 volumes of acetone and then resuspended in a $2 \mathrm{D}$ lysis buffer ( $8 \mathrm{M}$ urea, $2 \mathrm{M}$ thiourea, 4\% Chaps, $65 \mathrm{mM}$ DTT and $40 \mathrm{mM}$ Tris base). All $\mathrm{Ct}$ samples were combined to create a $\mathrm{Ct}$ sample mix and the same was done for samples BCAA. $150 \mu \mathrm{g}$ of protein from each sample mix were used to perform the 2D-electrophoresis analysis. Isoelectrofocusing was carried out with the IPGphor system (Ettan IPGphor isoelectric focusing system, GE Healtcare) using IPG gel strips $\mathrm{pH} 3-11 \mathrm{NL}, 13 \mathrm{~cm}$ long. Gel strips were rehydrated for 14 hours, at $30 \mathrm{~V}$ and $20^{\circ} \mathrm{C}$, in $250 \mu \mathrm{l}$ of reswelling buffer (8 $\mathrm{M}$ urea, $2 \mathrm{M}$ thiourea, 2\% Chaps, $0.1 \%$ tergitol NP7, Sigma) and focused at $20000 \mathrm{~V} / \mathrm{h}$ at $20^{\circ} \mathrm{C}$. After they were incubated $10 \mathrm{~min}$ in equilibration buffer (50 mM Tris pH 6.8, $6 \mathrm{M}$ urea, 30\% glycerol, 2\% SDS, 3\% iodoacetamide) before being applied on $15 \%$ SDS-Page gel without staking gel. The separation of protein spots was performed at $80 \mathrm{~V}$ for $17 \mathrm{~h}$ at room temperature.

After having been fixed for 2 hours in a fix solution (40\% ethanol, $10 \%$ acetic acid), the 2D gels were stained with fluorescent staining (Flamingo ${ }^{\text {тм }}$ fluorescent gel stain, Bio-Rad) for 3 hours and destained in $0.1 \%$ Tween 20 solution for $10 \mathrm{~min}$.

For each mix samples we obtained three different gels visualized by Typhoon laser scanner (GE Healtcare) and then analyzed with Platinum software (GE Healtcare). The software compared BCAA with $\mathrm{Ct}$ group by choosing a master gel used for the automatic matching of spots in other 2D-gels. At the end the analysis we obtained for each spot the normalized volume representing the protein amount. Then we averaged the volumes of the corresponding spots in three replicate gels getting spots that statistically changed $(\mathrm{p}<0.05)$.

Finally we compared our proteomic maps with those published on specific databases (ExPASy) in order to identify differentially expressed spots.

\section{Statistical analysis}

Statistical analysis was performed with GraphPad Prism $^{\circledR} 5.02$ software (GraphPad Software, San Diego, $\mathrm{CA})$. Results are expressed as means \pm standard deviation of the mean (SD). Statistical significance was calculated using unpaired Student's $t$-test. Statistical significance was set to $\mathrm{p}<0.05$.

\section{Results}

Representative 2-DE gels for $\mathrm{Ct}$ and BCAA are reported in Figure 1 and identity and fold changes of identified plasma proteins are reported in Table 1. By matching 2D gels from $\mathrm{Ct}$ and BCAA around 500 common spots were analyzed whereas only 10 spots appeared differentially expressed. Among them 8 appeared upregulated and identified as Apolipoprotein A-I (APOAI), Complement factor $\mathrm{B}$, Complement $\mathrm{C} 3$, Immunoglobulin light chain and 2 appeared downregulated identified as Alpha-1 -antitrypsin and unknown.

\section{Conclusions}

As far as we know this is the first available proteomic analysis of the plasma proteins expression profile after BCAA enriched mixture supplementation in mice.

Results showed that 1) a limited number of proteins changed expression in the plasma of supplemented in comparison with control unsupplemented animals; 2) 


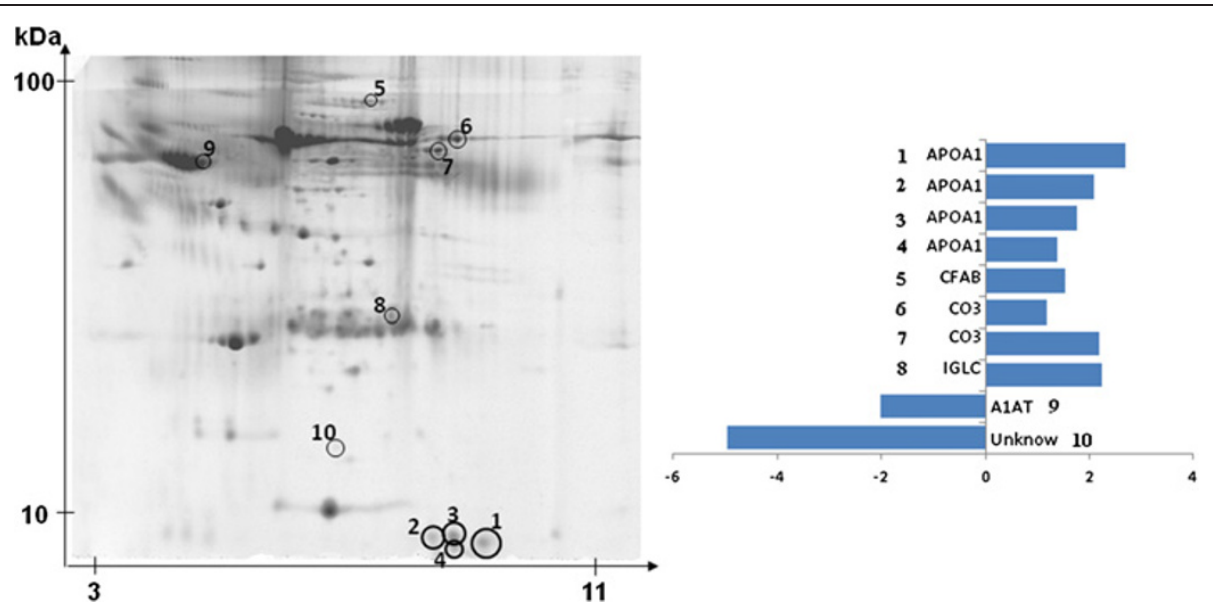

Figure 1 Example of typical 2-DE gel image of plasma proteins extract. Left, Changed spots circled and numbered. Right, Identified proteins and fold changes. APO A-I, Apolipoprotein A-l; CFAB, Complement Factor B; IGCL, Immunoglobulin light chain; A1AT, Alpha-1-antitrypsin.

four spots showed significant quantitative fold changes and were identified as Apolipoprotein A-I.

In our study the oral supplementation with BCAAem for four weeks was associated with a minor change of the 2-DE pattern profile as only 10 spots out of 500 appeared differentially expressed between supplemented and unsupplemented mice. In particular the upregulated spots were identified as Apolipoprotein A-I, Complement factor B, Complement C3, Immunoglobulin light chain whereas the downregulated spots were Alpha-1 -antitrypsin and an unidentified protein.

Apolipoprotein A-I is a major protein component of high density lipoprotein (HDL) in the plasma and participates to the reverse cholesterol transport (RCT) from tissues to liver where it can be excreted directly into the bile or metabolized into bile salts before excretion $[7,8]$. Lipid-poor Apo A-I/HDL are known to act as acceptors for cellular lipids, and lipid efflux from cells can be mediated via cell surface proteins (ABCA1, ABCG1 and SR-BI) [9]. RCT represents the foremost mechanism underlying the anti-atherogenic effects of Apo A-I. Apart from its participation to the RTC HDL/Apo A-I might exert their anti-atherogenic effects through several other mechanisms. For example, it has been demonstrated that HDL/Apo A-I have anti-inflammatory activity [10] being capable to reduce oxidized lipids and its inflammatory effects $[11,12]$.

In experimental studies using atherosclerosis-susceptible mice (inbred C57BL/6, used in the present study), it was observed that transgenic overexpression of human ApoAI significantly protected from development of early atherosclerotic lesions [13]. Similarly, overexpression of human ApoA-I in apoE-deficient transgenic mice suppressed early atherosclerotic lesions [14]. Furthermore, knocking out

Table 1 Identification of changed plasma protein following BCAAem supplementation by ExPASy

\begin{tabular}{lccccc}
\hline & Protein name & Protein name & Accession number & Fold change & Physiological function \\
\hline 1 & Apolipoprotein A-I & APOAI & Q00623 & 2.70 & Partecipates in RTC from tissues to liver \\
2 & Apolipoprotein A-I & APOAI & Q00623 & 2.10 & Partecipates in RTC from tissues to liver \\
3 & Apolipoprotein A-I & APOAI & Q00623 & 1.80 & Partecipates in RTC from tissues to liver \\
4 & Apolipoprotein A-I & APOAl & Q00623 & 1.38 & Partecipates in RTC from tissues to liver \\
5 & Complement factor B & CFAB & P04186 & 1.54 & Is part of the alternate pathway of the \\
complement system
\end{tabular}


apoA-I resulted in an accelerated atherosclerosis development in several animal models (i.e. the human apoBtransgenic female mice; the LDL receptor-deficient; the LDL receptor/apoE-deficient mice) $[15,16]$.

Taking into account that increasing ApoA-I production is now considered a target for coronary heart disease (CHD) risk reduction, beside pharmacological agents, several studies have focused on nutritional compounds affecting serum apoA-I concentration. For instance it has been found that, saturated fatty acids (SAFAs) and cis-monounsaturated fatty acids (cisMUFAs), lecithin (consisting of three phospholipids; phosphatidylcholine (PC), phosphatidylethanolamine (PE), and phosphatidylinositol (PI)) and moderate amounts of ethanol [17] increase serum ApoA-I concentrations [18] but the mechanisms underlying these changes remain to be fully elucidated. Beside the energydelivering nutrients diverse micronutrients, such as minerals (e.g. zinc, magnesium, and vanadate) and vitamins (e.g., vitamin $\mathrm{C}$, vitamin $\mathrm{D}$, vitamin $\mathrm{E}$, and vitamin $\mathrm{A}$, vitamin B3), might also enhance ApoA-I synthesis $[19,20]$. Anyhow whether these findings also hold for the in vivo situation remains to be confirmed [21]. In our study we describe, for the first time, an increased Apo A-I plasma concentration following BCAA enriched mixture supplementation in the wild type mouse. The likely role of essential amino acids in Apo A-I synthesis deserves future investigations.

In this study, we observed an increase in Complement C3 (CO3) and Complement Factor B (CFB) plasma proteins. CO3 plays a central role in the complement system activation. Its processing by $\mathrm{C} 3$ convertase is the central reaction in both classical and alternative complement pathways. After activation C3b can bind covalently via its reactive thioester to cell surface carbohydrates or immune aggregates [22]. Elevated C3 concentrations were associated with increased risk of impaired insulin sensitivity, insulin resistance, abdominal obesity and low HDL cholesterol compared to low C3 concentrations. Increased CHD risk conferred by elevated C3 concentrations is further accentuated among high dietary fat consumers and monounsaturated fat [23].

CFB is a fundamental component of the alternative complement pathway. Following the activation of alternative pathway factor $B$ is cleaved by complement factor $\mathrm{D}$ into 2 fragments of different molecular weight, $\mathrm{Ba}$ (noncatalytic chain) and $\mathrm{Bb}$ (catalytic chain). Both of these fragments express a variety of biological functions. In particular $\mathrm{Bb}$ is a serine protease that combines with complement factor $3 \mathrm{~b}$ to generate the C3 or C5 convertase. $\mathrm{Bb}$ is involved in the proliferation of preactivated $\mathrm{B}$ lymphocytes, while $\mathrm{Ba}$ inhibits their proliferation.
Factor B hyperconsumption and increased catabolism, concomitant with factor B fragment production, occurs in a wide variety of diseases, including gram-negative sepsis, autoimmune diseases and burns [24] whereas very few data are reported on the effects of dietary supplementations on CFB plasma levels $[25,26]$. An increased CFB concentration could enhance the immune response of the alternative pathway, by providing more factors B to be spun to generate more C3-convertase thus increasing the amount of its secondary reactions described above.

Although the significance of the observed changes and the underlying mechanisms deserve future investigations, the evidence of a contemporaneous increase of Apo A-I and Complement proteins allow us to speculate about a protective role of increased HDL following supplementation. In fact, in vitro studies indicate that HDL blocks the assembly of the terminal complement attack complex on endothelial cells [27]. Indeed the observed decrease in Alpha-1-antitrypsin (A1AT) a serine proteases inhibitor related to acute phase response [28] is probably a sign of the improvement in HDL protective capabilities sustained by BCAAem supplementation.

Finally in our analysis we found an increase in Immunoglobulin light chain (IgLC) levels. Studies have shown that IgLC can bind to mast cells facilitating their activation [29] thus contributing to the development of inflammatory disease. Furthermore excess of IgLC may modulate the apoptotic cell death of neutrophils thus contributing to increased susceptibility to bacterial infections in presence of renal failure [30,31]. Considering that only one spot identified as IgLC appeared to be increased following supplementation and that no signs of renal dysfunction have been detected following longterm BCAAem supplementation [32], quantitative and qualitative significance of the change observed in our study remains to be elucidated.

\section{Limitations of the study}

Our study has limitations. First our results are to be considered preliminary as only an age, 9 months corresponding to adulthood in mice, has been analyzed. Second, the identification of proteins was based on available proteome database in the mouse (ExPASy) and not on mass spectrometry. Anyhow we reckon that the latter limitation is not a major bias as, to date, available databases on proteome of mouse plasma are highly reliable. Furthermore a direct translation of results to human beings in unlikely as the daily dose usually adopted in mice $(0.1 \mathrm{gr} / \mathrm{gr} /$ day $)$ are around ten fold those suggested in humans $(0.1 \mathrm{gr} / \mathrm{kg} /$ day $)$, as in mice dose correction is made for the higher basal metabolism [33].

Notwithstanding these limitations, results from our study opens up a new avenue of research, aimed to 
identify the individual contributions of these molecular markers to the effects of BCAA enriched mixtures supplementations in mammals.

\section{Competing interests}

The authors declare non conflicts of interests.

\section{Authors' contributions}

LB participated in statistical analysis and manuscript preparation, AM participated in data collection, statistical analysis. GD served as the principal investigator and contributed to study design, data collection, and manuscript preparation. All authors read and approved the final manuscript.

Received: 16 November 2012 Accepted: 19 March 2013

Published: 3 April 2013

\section{References}

1. Houtkooper RH, Williams RW, Auwerx J: Metabolic networks of longevity. Cell, 142:9-14

2. D'Antona G, Ragni M, Cardile A, Tedesco L, Dossena M, Bruttini F, Caliaro F, Corsetti G, Bottinelli R, Carruba MO, Valerio A, Nisoli E: Branched-chain amino acid supplementation promotes survival and supports cardiac and skeletal muscle mitochondrial biogenesis in middle-aged mice. Cell Metab 2010, 12:362-372.

3. Shimomura Y, Murakami T, Nakai N, Nagasaki M, Harris RA: Exercise promotes BCAA catabolism: effects of BCAA supplementation on skeletal muscle during exercise. J Nutr 2004, 134(6 Suppl):1583S-1587S.

4. Bassit RA, Sawada LA, Bacurau RF, Navarro F, Martins E Jr, Santos RV, Caperuto EC, Rogeri P, Costa Rosa LF: Branched-chain amino acid supplementation and the immune response of long-distance athletes. Nutrition 2002, 18(5):376-379.

5. De Palo EF, Gatti R, Cappellin E, Schiraldi C, De Palo CB, Spinella P: Plasma lactate, $\mathrm{GH}$ and $\mathrm{GH}$-binding protein levels in exercise following BCAA supplementation in athletes. Amino Acids 2001, 20(1):1-11.

6. Lowry OH, Rosebrough NJ, Farr AL, Randall RJ: Protein measurement with the Folin phenol reagent. J Biol Chem 1951, 193:265-275.

7. Glomset JA: The plasma lecithins:cholesterol acyltransferase reaction. J Lipid Res 1968, 9:155-167.

8. Zhang Y, Zanotti I, Reilly MP, Glick JM, Rothblat GH, Rader DJ: Overexpression of apolipoprotein A-I promotes reverse transport of cholesterol from macrophages to feces in vivo. Circulation 2003, 108:661-663.

9. Yvan-Charvet $L$, Wang $N$, Tall AR: Role of HDL, ABCA1, and ABCG1 transporters in cholesterol efflux and immune responses. Arterioscler Thromb Vasc Biol 2010, 30:139-143.

10. Navab M, Imes SS, Hama SY, Hough GP, Ross LA, Bork RW, Valente AJ, Berliner JA, Drinkwater DC, Laks $\mathrm{H}$, et al: Monocyte transmigration induced by modification of low density lipoprotein in cocultures of human aortic wall cells is due to induction of monocyte chemotactic protein 1 synthesis and is abolished by high density lipoprotein. J Clin Invest 1991, 88:2039-2046

11. Garner B, Waldeck AR, Witting PK, Rye KA, Stocker R: Oxidation of high density lipoproteins. II. Evidence for direct reduction of lipid hydroperoxides by methionine residues of apolipoproteins Al and All. J Biol Chem 1998, 273:6088-6095.

12. Tall AR: Cholesterol efflux pathways and other potential mechanisms involved in the athero-protective effect of high density lipoproteins. J Intern Med 2008, 263:256-273.

13. Rubin EM, Krauss RM, Spangler EA, Verstuyft JG, Clift SM: Inhibition of early atherogenesis in transgenic mice by human apolipoprotein Al. Nature 1991, 353:265-267.

14. Plump AS, Scott CJ, Breslow JL: Human apolipoprotein A-I gene expression increases high density lipoprotein and suppresses atherosclerosis in the apolipoprotein E-deficient mouse. Proc Natl Acad Sci USA 1994, 91:9607-9611.

15. Moore RE, Kawashiri MA, Kitajima K, Secreto A, Millar JS, Pratico D, Rader DJ: Apolipoprotein A-I deficiency results in markedly increased atherosclerosis in mice lacking the LDL receptor. Arterioscler Thromb Vasc Biol 2003, 23:1914-1920.

16. Voyiaziakis E, Goldberg IJ, Plump AS, Rubin EM, Breslow JL, Huang LS: ApoA-I deficiency causes both hypertriglyceridemia and increased atherosclerosis in human apoB transgenic mice. J Lipid Res 1998, 39:313-321.
17. van der Gaag MS, van Tol A, Vermunt SH, Scheek LM, Schaafsma G, Hendriks HF: Alcohol consumption stimulates early steps in reverse cholesterol transport. J Lipid Res 2001, 42:2077-2083.

18. Mensink RP, Zock PL, Kester AD, Katan MB: Effects of dietary fatty acids and carbohydrates on the ratio of serum total to HDL cholesterol and on serum lipids and apolipoproteins: a meta-analysis of 60 controlled trials. Am J Clin Nutr 2003, 77:1146-1155.

19. Ganji SH, Kamanna VS, Kashyap ML: Niacin and cholesterol: role in cardiovascular disease (review). J Nutr Biochem 2003, 14:298-305.

20. Mooradian AD, Haas MJ, Wong NC: The effect of select nutrients on serum high-density lipoprotein cholesterol and apolipoprotein A-I levels. Endocr Rev 2006, 27:2-16.

21. Dullens SP, Plat J, Mensink R: Increasing apoA-I production as a target for CHD risk reduction. Nutr Metab Cardiovasc Dis 2007, 17:616-628.

22. Carroll MC: Complement and humoral immunity. Vaccine 2008 Suppl 8:28-33.

23. Phillips CM, Kesse-Guyot E, Ahluwalia N, McManus R, Hercberg S, Lairon D, Planells R, Roche HM: Dietary fat, abdominal obesity and smoking modulate the relationship between plasma complement component 3 concentrations and metabolic syndrome risk. Atherosclerosis 2012, 220:513-519.

24. Kolb WP, Morrow PR, Tamerius JD: $B a$ and Bb fragments of factor $B$ activation: fragment production, biological activities, neoepitope expression and quantitation in clinical samples. Complement Inflamm 1989, 6:175-204.

25. Duthie SJ, Horgan G, de Roos B, Rucklidge G, Reid M, Duncan G, Pirie L, Basten GP, Powers HJ: Blood folate status and expression of proteins involved in immune function, inflammation, and coagulation: biochemical and proteomic changes in the plasma of humans in response to long-term synthetic folic acid supplementation. J Proteome Res 2010, 9:1941-1950.

26. Gmunder FK, Joller PW, Joller-Jemelka HI, Bechler B, Cogoli M, Ziegler WH, Muller J, Aeppli RE, Cogoli A: Effect of a herbal yeast food supplement and long-distance running on immunological parameters. Br J Sports Med 1990, 24:103-112

27. Hamilton KK, Zhao J, Sims PJ: Interaction between apolipoproteins A-I and A-II and the membrane attack complex of complement. Affinity of the apoproteins for polymeric C9. J Biol Chem 1993, 268:3632-3638.

28. Vaisar T, Pennathur S, Green PS, Gharib SA, Hoofnagle AN, Cheung MC, Byun J, Vuletic S, Kassim S, Singh P, Chea H, Knopp RH, Brunzell J, Geary R, Chait A, Zhao XQ, Elkon K, Marcovina S, Ridker P, Oram JF, Heinecke JW: Shotgun proteomics implicates protease inhibition and complement activation in the antiinflammatory properties of HDL. J Clin Invest 2007, 117:746-756.

29. Redegeld FA, van der Heijden MW, Kool M, Heijdra BM, Garssen J, Kraneveld $A D$, Van Loveren H, Roholl P, Saito T, Verbeek JS, Claassens J, Koster AS, Nijkamp FP: Immunoglobulin-free light chains elicit immediate hypersensitivity-like responses. Nat Med 2002, 8:694-701.

30. Cohen G: Immunoglobulin light chains in uremia. Kidney Int 2003:S15-S18.

31. Cohen $G$, Horl WH: Free immunoglobulin light chains as a risk factor in renal and extrarenal complications. Semin Dial 2009, 22:369-372.

32. Corsetti G, Stacchiotti A, D'Antona G, Nisoli E, Dioguardi FS, Rezzani R: Supplementation with essential amino acids in middle age maintains the health of rat kidney. Int J Immunopathol Pharmacol 2010, 23:523-533.

33. Pellegrino MA, Brocca L, Dioguardi FS, Bottinelli R, D'Antona G: Effects of voluntary wheel running and amino acid supplementation on skeletal muscle of mice. Eur J Appl Physiol 2005, 93:655-664.

doi:10.1186/1550-2783-10-19

Cite this article as: Brocca et al:: Proteomic analysis of plasma after branched chain enriched mixture supplementation in mice. Journal of the International Society of Sports Nutrition 2013 10:19. 